\title{
EVAluation of two PCR-based techNiQues FOR MOLECULAR EPIDEMIOLOGY IN FINLAND, A HIGH-ENDEMIC AREA WITH FOUR SYMPATRIC TRICHINELLA SPECIES
}

\author{
KAPEL C.M.O.*, OIVANEN L.*****, LA ROSA G. ${ }^{* * * *}$, MIKKONEN T.** \& POZIO E.****
}

\begin{abstract}
Summary :
Trichinella larvae collected from wildlife, domestic and synanthropic animals in Finland were identified to species by two molecular techniques: Random amplified polymorphic DNA (RAPD) polymerase chain reaction (PCR) and the recently described multiplex PCR. The RAPD-PCR was very sensitive to the sub-optimal preservation muscle larvae and resulting in weak and smeared bands on the gels for such material. However, the same samples yielded easily recognizable bands in the multiplex PCR; this latter technique is then recommended for epidemiological studies, especially when the preservation of the samples is sub-optimal. For larvae in good condition the unequivocal bands obtained by multiplex was the easiest identifiable. Four species of Trichinella were identified in the material: T. spiralis, T. nativa, T. britovi, and T. pseudospiralis. Trichinella britovi is a new record for Finland, and T. pseudospiralis is a new record for Northern Europe. Mixed infections between $T$. britovi and $T$. spiralis, $T$. nativa and $T$. spiralis, and between $T$. britovi and T. nativa were detected; this is the first record of a mixed infection between $T$. spiralis and T. nativa in a naturally infected host. Raccoon dogs were the only host species from which all of the four Trichinella species were detected. Trichinella spiralis was found in both domestic animals and wildlife, but none of the sylvatic Trichinella species were detected in domestic pig.
\end{abstract}

KEY WORDS : RAPD-PCR, multiplex PCR, epidemiology, Trichinella spiralis, Trichinella nativa, Trichinella britovi, Trichinella pseudospiralis.

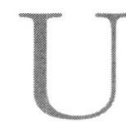
p to now, species determination of Trichinella spp. in epidemiological studies have mainly employed random amplified polymorphic DNA (RAPD) polymerase chain reaction (PCR) analysis (Bandi et al., 1995), but the reproducibility of the RAPD-PCR has been questioned because the technique is relatively sensitive to sub-optimally preserved samples (Pozio et al., 1999). Similarly, it has been demonstrated from experimentally infected pigs that sylvatic species of Trichinella may be difficult to iden-

\footnotetext{
* Danish Centre for Experimental Parasitology, Ridebanevej 3, DK1870 Frederiksberg C, Denmark.

** Department of Basic Veterinary Sciences, Faculty of Veterinary Medicine, University of Helsinki, P.O. Box 57, FIN-00014 Helsinki, Finland.

*** National Veterinary and Food Research Institute, PO Box 368, FIN-00231 Helsinki, Finland.

***** Laboratory of Parasitology, Istituto Superiore di Sanità, viale Regina Elena 299, I-00161 Rome, Italy.

Correspondence: Christian Kapel. Fax: + 4535282778 .

E-mail: chk@kvl.dk
}

tify by RAPD-PCR, presumably due to incomplete development in the pig muscle tissue (Pozio et al., 1999). Recently, Zarlenga et al. (1999) introduced a less equivocal technique for simultaneous differentiation of all genotypes of Trichinella.

It is evident from previous studies that Southern Finland is a high endemic area for sylvatic and domestic trichinellosis (Hirvelä-Koski et al., 1985; Oivanen \& Oksanen, 1994; Mikkonen et al., 1997; Oksanen et al., 1998), although none of the studies have used molecular techniques for differentiation of Trichinella species in the Finnish wildlife and domestic animals. Because of the exceptionally high regional prevalence in wildlife (Oivanen \& Oksanen, 1994; Oksanen et al., 1998) and recurrent infections in domestic swine (Oivanen \& Oksanen, 1994), southern Finland presents an ideal opportunity for studies on the molecular epidemiology of Trichinella.

The aims of the present study were to evaluate two techniques for molecular epidemiology in an area with sympatric species of Trichinella. It is the first time this multiplex PCR technique is used for an epidemiological study.

\section{MATERIALS AND METHODS}


uscle samples were collected in Southern Finland (1993-1997) from nine host species (bears, wolves, foxes, lynx, raccoon dogs, wild boars, domestic pigs, rats and cats). After initial examination, 87 muscle samples positive for Trichinella were stored at $-20^{\circ} \mathrm{C}$. However, all samples from rats were used for other purposes prior to the present study and were therefore thawed twice.

Muscle larvae were released by $\mathrm{HCl}$ pepsin digestion and recovered larvae were stored in $70 \%$ ethyl-alcohol and stored at $-20^{\circ} \mathrm{C}$. Prior to molecular analysis, larvae were rehydrated in a series of alcohol and single larvae were finally placed in $5 \mu \mathrm{l}$ sterile water. The condition of the larvae, was determined from the appearance of the larvae. Coiled and partly uncoiled larvae were described as in moderate condition and 
C-shaped larvae with a transparent appearance as in bad condition.

Molecular identification was done as a blind study in two laboratories each with one PCR-derived techniques: Random amplified polymorphic DNA (RAPD) polymerase chain reaction (PCR) was done at the Danish Centre for Experimental Parasitology and multiplex PCR at the International Trichinella Reference Centre (ITRC). For each muscle isolate, three or more larvae were tested by each of the methods, except for a few samples where fewer larvae were available; in these instances all larvae available were tested.

The RAPD-PCR was done according to Bandi et al. (1995) using primer 494 (AGCGCTGTGAGAAAGATGAAAGAT) at the Danish Centre for Experimental Parasitology. Larvae of reference strains T. spiralis (code ISS4), T. nativa (ISS42), and T. britovi (ISS100) were included in each reaction and resulting gel. Initially, T. pseudospiralis was not expected to be found in Finland and was not included as a reference in the RAPD-PCR.

The multiplex PCR was modified from Zarlenga et al. (1999) according to a protocol developed at the ITRC. Briefly, a solution of $0.1 \mathrm{M}$ Tris- $\mathrm{HCl} \mathrm{pH} 7.6$ was added to the larva, overlaid with mineral oil, heated at $90^{\circ} \mathrm{C}$ for $10 \mathrm{~min}$, treated with proteinase $\mathrm{K}$ (final concentration: $10 \mathrm{mg} / \mathrm{ml}$ ) at $55^{\circ} \mathrm{C}$ for three hours, and heated again at $90^{\circ} \mathrm{C}$ for $10 \mathrm{~min}$. PCR was performed using Taq DNA polymerase, $10 \mathrm{X}$ PCR buffer, and dNTPs, from Takara (Japan), preparing $50 \mu \mathrm{l}$ containing a final concentration of $1.5 \mathrm{mM} \mathrm{MgCl}_{2}$ (included in the Takara 10X PCR buffer), $0.2 \mathrm{mM}$ dNTPs, 0.5 unit of Taq DNA polymerase, and 50 pmoles of each of five primer pairs (I: 5'-GTTCCATGTGAACAGCAGT + 5'-CGAAAACATACGACAACTGC, II: 5'-GCTACATCCTTTTGATCTGTT + 5'-AGACACAATATCAACCACAGTACA, III: 5'GCGGAAGGATCATTATCGTGTA + 5-TGGATTACAAAGAAAACCATCACT, IV: 5'-GTGAGCGTAA-
TAAAGGTGCAG + 5'-TTCATCACACATCTTCCACTA, $\mathrm{V}: 5^{\prime}$-CAATTGAAAACCGCTTAGCGTGTTT + 5'-TGATCTGAGGTCGACATTTCC).

For amplification, $4 \mu \mathrm{l}$ of $10 \mu \mathrm{l}$ of a single larva preparation were used according to Pozio et al. (1999). Amplifications consisted of 35 cycles, as follows: denaturation at $94^{\circ} \mathrm{C}$ for $20 \mathrm{~s}$, annealing at $58^{\circ} \mathrm{C}$ for one minute, and elongation at $72^{\circ} \mathrm{C}$ for one minute. For the comparison, ML of reference strains for T. spiralis (code ISS3), T. nativa (ISS10), T. britovi (ISS2), and T. pseudospiralis (ISS13), were used.

The kappa coefficient $(\mathrm{K})$ was used to describe and to test the degree of agreement between RAPD and multiplex species identification. Fishers exact test was used to test if RAPD-PCR was influenced by the preservation of the larvae.

\section{RESULTS}

$\mathrm{n}$ overall agreement was obtained for species
identification of Trichinella larvae with both the
RAPD-PCR and the multiplex PCR ( $\mathrm{K}=0.691$, SE $0.064, p<0.001$, proportion of matches (agreements) $69 / 87=0.793$, proportion of matches expected by chance $=0.330$ ). However, it was obvious that the RAPD-PCR was very sensitive to the physical condition of the Trichinella larvae (Fishers Exact test, $\mathrm{P}<0.001$ ), and that bands of $T$. spiralis and T. britovi were difficult to distinguish from each other in the RAPD-PCR (Tables I and II). In contrast, the simple band patterns produced by the multiplex PCR allowed for faster and less subjective identification of species specific bands. Larvae judged as in bad condition (uncoiled and transparent) gave weak and smeared bands in the RAPDPCR (Fig. 1). With the same samples, the multiplex PCR produced bands for which both molecular weight and

\begin{tabular}{|c|c|c|c|c|c|c|c|c|c|c|c|c|c|c|c|c|c|c|c|c|}
\hline & \multicolumn{2}{|c|}{ Bear } & \multicolumn{2}{|c|}{ Cat } & \multicolumn{2}{|c|}{ Fox } & \multicolumn{2}{|c|}{ Lynx } & \multicolumn{2}{|c|}{ Racoon dog } & \multicolumn{2}{|c|}{ Rat } & \multicolumn{2}{|c|}{ Wild boar } & \multicolumn{2}{|c|}{ Wolf } & \multicolumn{2}{|c|}{ Pig } & \multicolumn{2}{|c|}{ Total } \\
\hline & $\mathrm{R}$ & M & $\mathrm{R}$ & M & $\mathrm{R}$ & M & $\mathrm{R}$ & M & $\mathrm{R}$ & M & $\mathrm{R}$ & M & $\mathrm{R}$ & M & $\mathrm{R}$ & M & $\mathrm{R}$ & M & $\mathrm{R}$ & M \\
\hline T. spiralis & & & $1^{*}$ & 2 & 1 & 1 & & & 6 & 5 & 16 & 28 & 2 & 2 & & & 9 & 10 & 35 & 48 \\
\hline T. nativa & 3 & 3 & & & 10 & 10 & 3 & 3 & 11 & 11 & & & & & 1 & 1 & & & 28 & 28 \\
\hline T. britovi & & & & & & & & & & & & & & & & & & & 0 & 0 \\
\hline T. pseudospiralis & & & & & & & & & 4 & 4 & & 1 & 1 & 1 & & & & & 5 & 6 \\
\hline T. spiralis $+T$. britovi & & & 1 & & & & & & 1 & 2 & & & & & & & & & 2 & 2 \\
\hline T. spiralis $+T$. nativa & & & & & 1 & 1 & & & 1 & & & & & & 1 & & & & 3 & 1 \\
\hline$T$. nativa $+T$. britovi & & & & & & & & & & 1 & & & & & & 1 & & & 0 & 2 \\
\hline Unclear bands & & & & & & & & & & & 13 & & & & & & 1 & & $14^{* *}$ & 0 \\
\hline Total & & & & & & & & & & & & & & & & & & & 87 & 87 \\
\hline
\end{tabular}

R: RAPD-PCR (Bandi et al., 1995).

M: Multiplex PCR (Zarlenga et al., 1999).

*: Number of positive samples.

**: All frozen and thawed twice: Trichinella larvae in bad condition (Uncoiled or transparent).

Table I. - Species identification of Trichinella from nine host species by two PCR methods. 


\begin{tabular}{|c|c|c|c|c|c|c|c|c|c|c|}
\hline & & \multicolumn{9}{|c|}{ Multiplex PCR } \\
\hline & & T. spiralis & T. nativa & T. britovi & $\begin{array}{l}\text { T. pseudo- } \\
\text { spiralis }\end{array}$ & $\begin{array}{l}\text { T. spiralis } \\
+ \text { T. britovi }\end{array}$ & $\begin{array}{l}\text { T. spiralis } \\
+ \text { T. nativa }\end{array}$ & $\begin{array}{l}\text { T. nativa } \\
+T \text {. britovi }\end{array}$ & $\begin{array}{l}\text { Unclear } \\
\text { bands }\end{array}$ & Total \\
\hline \multirow{9}{*}{ RAPD-PCR } & T. spiralis & 34 & & & & 1 & & & & 35 \\
\hline & T. nativa & & 28 & & & & & & & 28 \\
\hline & T. britovi & & & 0 & & & & & & 0 \\
\hline & T. pseudospiralis & & & & 5 & & & & & 5 \\
\hline & T. spiralis $+T$. britovi & 1 & & & & 1 & & & & 2 \\
\hline & T. spiralis $+T$. nativa & & & & & & 1 & 2 & & 3 \\
\hline & T. nativa $+T$. britovi & & & & & & & & & 0 \\
\hline & Unclear bands & 13 & & & 1 & & & & & 14 \\
\hline & Total & 48 & 28 & 0 & 0 & 2 & 1 & 2 & 0 & 87 \\
\hline
\end{tabular}

Table II. - Comparison of test results of 87 individual muscle samples.

similarity to the reference strains were easy to interpret (Fig. 2). Highest discrepancy between the methods were often found in the differentiation of $T$. spiralis

a)

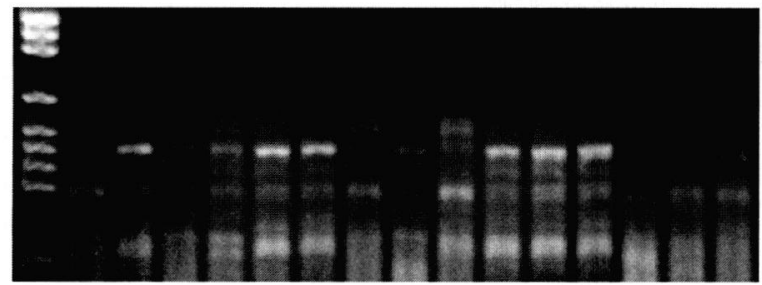

$\begin{array}{llllllllllllllll}\mathrm{M} & \mathrm{T}_{1} & \mathrm{~T}_{2} & \mathrm{~T}_{3} & 5 & 6 & 7 & 8 & 9 & 10 & 11 & 12 & 13 & 14 & 15 & 16\end{array}$

b)

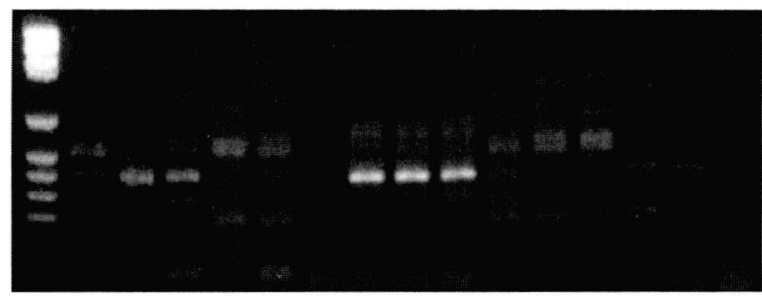

$\begin{array}{llllllllllllllll}M & \mathrm{~T}_{1} & \mathrm{~T}_{2} & \mathrm{~T}_{3} & 5 & 6 & 7 & 8 & 9 & 10 & 11 & 12 & 13 & 14 & 15 & 16\end{array}$

c)

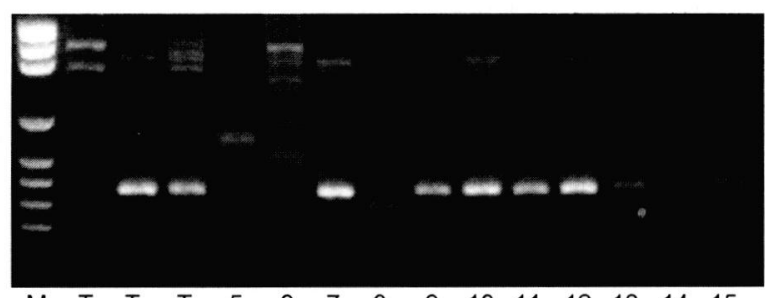

$\begin{array}{lllllllllllllll}\mathrm{M} & \mathrm{T}_{1} & \mathrm{~T}_{2} & \mathrm{~T}_{3} & 5 & 6 & 7 & 8 & 9 & 10 & 11 & 12 & 13 & 14 & 15\end{array}$

Fig. 1. - a-c: Examples of RAPD-PCR patterns obtained with crude preparations of individual Trichinella muscle larvae. Lanes: M: 100 bp ladder (PGEM); Reference larvae: T1, Trichinella spiralis (ISS4), T2: Trichinella nativa (ISS42), T3: Trichinella britovi (ISS100),

a: Lanes: 5-7 (wolf): $1 \times$ T. spiralis, $2 \times$ T. nativa, 8-10 (cat): $1 \times$ T. britovi, 2x T. spiralis,11-13 (raccoon dog): 3x T. nativa,14-16 (raccoon $\mathrm{dog}): 3 \mathrm{x}$ T. spiralis.

b: Lanes: 5-7 (pig): 2x T. spiralis (7: no product), 8-10 (lynx): 3x $T$. nativa,11-13 (pig): $3 \mathrm{x}$ T. spiralis, 14-16 (wild boar): $3 \mathrm{x}$ T. pseudospiralis.

C: Lanes: 5-7 (fox): 1x T. spiralis, 1x T. nativa (5: unclear), 8-10 (fox): 2x T. nativa (8: unclear), 11-13 (bear): $3 \mathrm{x}$ T. nativa, $14+15$ (rat) unclear (C-shaped and transparent larvae). from $T$. britovi and visa versa. Except for badly preserved larvae, there were no significant differences between the two methods for differentiating $T$. pseudospiralis and T. nativa.

Four species of Trichinella were identified from the nine host species: T. spiralis, T. nativa, T. britovi, and T. pseudospiralis (Table I). Raccoon dogs were the only host species from which all of four Trichinella species were identified. Foxes and wolves had T. spiralis and T. nativa, cats T. spiralis and T. britovi, rats and wild boars T. spiralis and T. pseudospiralis, pigs only T. spiralis, and lynx and bear only $T$. nativa. Mixed infections were found in raccoon dogs, foxes, wolves, and cats. None of the mixed infections contained more than two Trichinella species (T. spiralis $+T$. britovi, T. spiralis $+T$. nativa, T. britovi $+T$. nativa), and T. pseudospiralis was never found in mixed infections.

\section{DISCUSSION}

$\mathrm{F}$ rom the present study it is clear that in epidemiological studies the multiplex PCR has the advantage over the RAPD-PCR in being faster and easier to interpret due to a simple and distinct band pattern but also that this technique is less subjective and much less influenced by sub-optimal preservation of the parasite material. This difference was most obvious in the detection of mixed infections, but due to the relative few individual larvae tested, the variation might also be explained by chance. Since the two PCR techniques differ mainly with regard to primer composition and are equally laborious, the multiplex PCR can be recommended for epidemiological studies. Thus, even though the correlation between the two tests is high under ideal conditions, the multiplex PCR permits more reliable identification of material that has been frozen and thawed repeatedly and subsequently preserved in ethanol.

For epidemiological studies, sub-optimally preserved samples may be frequent, and the multiplex PCR pro- 
a)

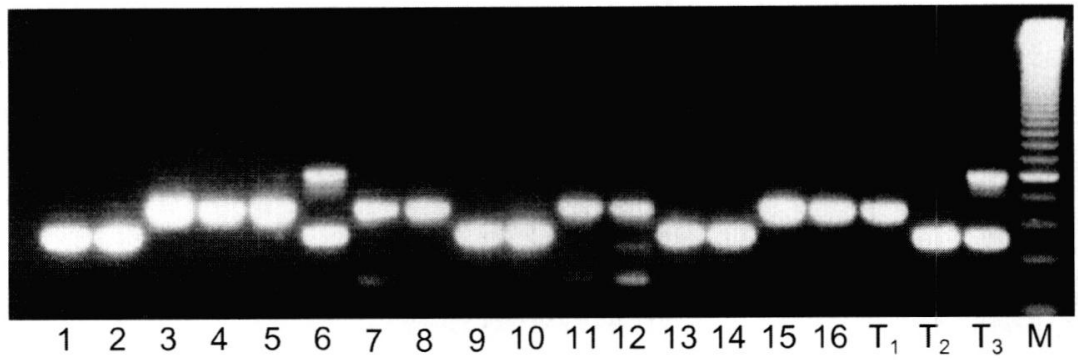

b)

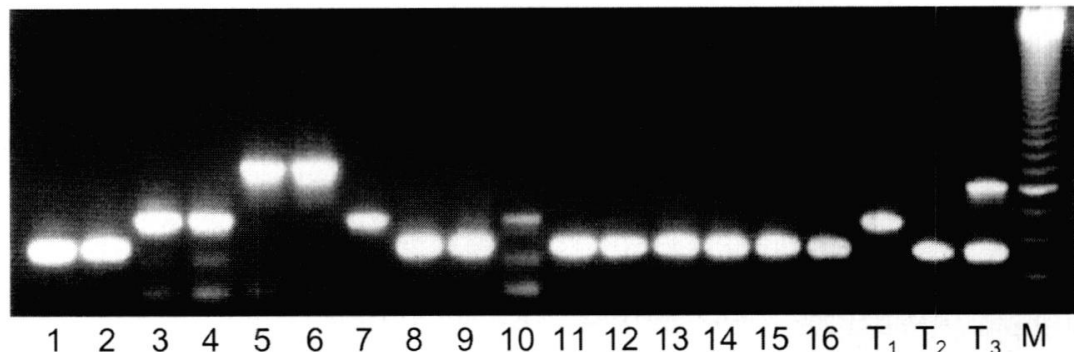

Fig. 2. - a-b: Examples of multiplex PCR patterns obtained with crude preparations of individual Trichinella muscle larvae. Reference larvae: T1, Trichinella spiralis; T2, Trichinella nativa; T3, Trichinella britovi. M: 100 bp ladder (Amersham-Pharmacia biotech)

a: Lanes: $1+2$ (fox): T. nativa; $3+4$ (pig), T. spiralis; $5+6$ (Raccoon dog), T. spiralis and $T$. britovi; $7+8$ (rat), T. spiralis; lanes 9+10 (raccoon dog), T. nativa; $11+12$ (pig), T. spiralis; $13+14$ (raccoon dog), T. nativa; $15+16$ (raccoon dog), T. spiralis

b: Lanes: $1+2$ (fox): T. nativa; $3+4$ (rat): $T$. spiralis; lanes 5+6 (raccoon dog): T. pseudospiralis, 7 (pig), T. spiralis; $8+9$ (raccoon dog): T. nativa; 10 (rat), T. spiralis; $11+12$ (fox), T. nativa; $13+14$ (fox), T. nativa; $15+16$ (fox), T. nativa. vides a major advantage for the utilisation of valuable material. For example, due to repeated thawing and freezing, half of the present rats samples (13 of 28) would not have given interpretable results in the RAPD-PCR and left room for speculation. Under routine conditions, when Trichinella is found, larvae might not be preserved immediately or simply stored refrigerated in water.

Whereas T. spiralis and T. nativa have previously been found in Finland, T. britovi and T. pseudospiralis are new records for Finland. Further, T. pseudospiralis is found for the first time in Northern Europe. As in other highly endemic areas, the present study demonstrated that rats, cats, foxes, raccoon dogs, and wild boars may be infected with the domestic species $T$. spiralis, but still we have evidence that it is maintained there and transmitted back to the domestic environment. The absence of sylvatic Trichinella in domestic pigs might have several epidemiological explanations, but might also be explained by the very limited infectivity of T. nativa, T. britovi, and T. pseudospiralis in experimentally infected pigs and wild boars (Kapel \& Gamble, 2000; Kapel, 2000). The detection of T. pseudospiralis in one sylvatic wild boar, could be the result of host malnourishment, environmental stress or other immuno-suppressing factors in the natural habitat, as suggested for observations of $T$. nativa in other naturally infected wild boars (Pozio \& Kapel, 1999).

Not surprisingly, T. nativa is the most prevalent of the sylvatic Trichinella species, probably because of its high freeze resistance in naturally infected carnivores (Kapel et al., 1999) and the sub-arctic climate of Fin- land. The absence of $T$. nativa in the rat population is most likely explained by its limited infectivity to rats (Pozio et al., 1992), and the synanthropic nature of this rodent.

Concurrent infections have previously been described with $T$. britovi and $T$. nativa in raccoon dogs and foxes (Pozio et al., 1995, 1998) and with T. spiralis and T. britovi in wild boars (Pozio et al., 1997), but it is the first time that mixed infections with $T$. spiralis and $T$. nativa have been found. The natural occurrence of such mixed infections may imply that protective immunity from an initial infection may not always persist. The finding that mixed infections occurred most frequently in raccoon dogs is in accordance with its scavenging nature; it was the only host from which all four Trichinella species were recovered.

The relatively high prevalence of the non-encapsulating T.pseudospiralis is surprising since the species has never previously been recorded from the Northern part of Western Europe. The epidemiology of this species is not clear, but as the only Trichinella species able to infect birds, its transmission potential might be underestimated. Its apparent wide distribution in Europe should be considered as a threat to human health in light of the low sensitivity of the classical compressorium technique in the detection of nonencapsulating Trichinella. Trichinella pseudospiralis in meats of feral pigs have been reported as the source of human trichinellosis (Jongwutiwes et al., 1998; Ranque et al., 2000).

Because we have identified four species of Trichinella in Finland, more comprehensive animal prevalence stu- 
dies from all Finnish provinces need to be conducted in order to clarify the epidemiology of this zoonosis. Such studies would contribute importantly to the understanding of the transmission of trichinellosis between wildlife and production animals in highly endemic areas sympatric for several Trichinella species.

\section{ACKNOWLEDGEMENTS}

The financial support from the Research and Science Foundation of Farmos and the Finnish Veterinary Science Foundation, and the co-operation of Dr Valkama, University of Turku are acknowledge. Also the Danish National Research Foundation contributed to this study. Mr. M. Amati is thanked for technical assistance at the ITRC.

\section{REFERENCES}

Bandi C., La Rosa G., Bardin M.G., Damiani G., Comincini S., TAsciotti L. \& Pozio E. Random amplified polymorphic DNA fingerprints of the eight taxa of Trichinella and their comparison with allozyme analysis. Parasitology, 1995, 110, 401-407.

Hirvelä-Koski V., Aho M., Asplund K., Hatakka M. \& Hirn J. Trichinella spiralis in wild animals, cats, mice, rats and farmed fur animals in Finland. Nordisk Veterinaermedicin, 1985, 37, 234-242.

Jongwutiwes S., Chantachum N., Kraivichian P., Siriyasatien P., Putaporntti C., Tamburrint A., La Rosa G., SReesunpasirikul C., YingYourd P. \& Pozio E. First outbreak of human trichinellosis caused by Trichinella pseudospiralis. Clinical Infectious Diseases, 1998, 26, 111-115.

KAPEL C.M.O. Sylvatic and domestic Trichinella spp. in wild boars; infectivity, muscle larvae distribution, and antibody response. The Journal of Parasitology (in press).

KAPEL C.M.O. \& GAMBLE H.R. Infectivity, persistence, and antibody response to domestic and sylvatic Trichinella spp. in experimentally infected pigs. International Journal for Parasitology, 2000, 30, 215-221.

Kapel C.M.O., Pozio E., SACChI L. \& Prestrud P. Freeze tolerance, morphology, and RAPD-PCR identification of Trichinella nativa in naturally infected arctic foxes. The Journal of Parasitology, 1999, 85, 144-147.

Mikkonen T., Oivanen L., Wihlman H. \& Haukisalmi V. Trichinellosis in rats (Rattus norvegicus) in Finland - Research in 12 Finnish refuse dumps, in: Trichinellosis. OrtegaPierres M.G., Gamble H.R., van Knapen F. \& Wakelin D. (eds), Centro de Investigación y Estudios Avanzados del Instituto Politécnico Nacional México, Mexico City, 1997, 551-558.

OIVANEN L. \& OKSANen A. Trichinellosis in domestic swine and wildlife in Finland, in: Trichinellosis. Campbell W.C., Pozio E. \& Bruschi F. (eds), Istituto Superiore di Sanità Press, Rome, Italy, 1994, 569-574.
Oksanen A., Lindgren E. \& TunkKari P. Epidemiology of trichinellosis in lynx in Finland. Journal of Helminthology, 1998, 72, 47-53.

Pozio E., Bandi C., la Rosa G., Jarvis T., Miller I. \& Kapel C.M. Concurrent infection with sibling Trichinella species in a natural host. International Journal for Parasitology, 1995, 25, 1247-1250.

POZIO E. \& KAPEL C.M.O. Trichinella nativa in sylvatic wild boar. Journal of Helmintbology, 1999, 73, 87-89.

Pozio E., Kapel C.M.O. \& Gamble H.R. Specificity and sensitivity of random amplified polymorphic DNA analysis for the identification of single larvae of Trichinella after experimental infection of pigs. Parasitology Research, 1999, 85, 504-506.

Pozio E., La Rosa G., Rossi P. \& Murrell K.D. Biological characterization of Trichinella isolates from various host species and geographical regions. The Journal of Parasitology, 1992, 78, 647-653.

Pozio E., Miller I., Jarvis T., Kapel C.M.O. \& La Rosa G. Distribution of sylvatic species of Trichinella in Estonia according to climate zones. The Journal of Parasitology, 1998, 84, 193-195.

Pozio E., Owen I.L., La Rosa G., Sacchi L., Rossi P. \& Corona S. Trichinella papuae n. sp. (Nematoda), a new non-encapsulated species from domestic and sylvatic swine of Papua New Guinea. International Journal for Parasitology, 1999, 29, 1825-1839.

Pozio E., Serrano F.J., la Rosa G., Reina D., Perez M.E. \& NAVARRETE I. Evidence of potential gene flow in Trichinella spiralis and in Trichinella britovi in nature. The Journal of Parasitology, 1997, 83, 163-166.

Ranque S., Faugere B., Pozio E., La Rosa G., Tamburrini A., Pellissier J.F. \& Brouqui P. Trichinella pseudospiralis outbreak in France. Emerging Infectious Diseases, 2000, 6, 543547.

Zarlenga D.S., Chute M.B., Martin A. \& Kapel C.M.O. A multiplex PCR for unequivocal differentiation of all encapsulated and non-encapsulated genotypes of Trichinella. International Journal for Parasitology, 1999, 29, 18591867. 